\title{
Expert System Software to Identify Damages Cars with Forward Chaining Method
}

\author{
Husaini $^{1}$, Yuswardi ${ }^{2}$ \\ ${ }^{1,2}$ Universitas Jabal Ghafur, Aceh, Indonesia \\ yuswardi@unigha.ac.id
}

\begin{abstract}
This study shows for the development of expert system software to identify damage to the car that can display information in the form of a solution of the damage. This system was developed using PHP and MySQL software. This system works to be able to present damage identification information on the car that can provide the most actual solution to the consul, as well as present a detailed report when consultations have been made. The purpose of this expert system is to facilitate car users in knowing damage to cars, as well as facilitate car users in identifying damage to cars, so they can update knowledge in the form of symptoms and damage. The diagnosis made by the counselor is: a counselor registers before making the diagnosis. Then answer the questions that have been provided. Furthermore, after making a diagnosis, the results can be printed through the printer.
\end{abstract}

Keywords: software; expert system; car damage; forward chaining

\section{Introduction}

At this time, transportation is clearly a very basic need. Already many people use transportation to carry out their daily activities, mobility is almost impossible if they do not use transportation. Most people now have made cars as the main means of transportation. Using a car can save time and money to get to your destination. However, constraints often occur from the car that causes damage so that it can interfere with the activities to be carried out. Many car drivers do not know the damage constraints experienced by the car. The problem for motorists, who do not know the type of damage, will be very fatal if the type of damage is not immediate addressed.

In general, some motorists who do not understand the disturbance or damage to their car, tend to leave it to the mechanics, regardless of whether the damage is simple or too complicated to repair. With all the solid and full activities, especially in big cities, it has demanded the community to do everything quickly and accurately. Time has become the main capital that is very valuable. Maintenance that is usually done alone, and without having to come to the garage with the vehicle, will be very helpful, especially for people who do not know about automotive and do not have time to come to the garage to wait until the vehicle has been repaired.

The expert system is enough to help some of the problems that exist in everyday life. Therefore, at this time it is possible that the application of an expert system that can identify car damage will be of little help, especially for vehicle owners who are still unfamiliar with the type of car damage as well as the tight time and the presence of workshops that are still rare for remote areas. In order to provide a solution to a problem, it requires "Expert System Software to Identify Damage to the Car".

\section{Review of Literature}

\subsection{Expert System, Forward Chaining Method}

Expert system. Kusumadewi (2003: 110), Expert system (expert system) is a system that seeks to adopt human knowledge to computers so that computers can solve problems 
as is usually done by experts. With an expert system, ordinary people can solve quite complex problems, even though the real thing can only be solved with the help of experts. For experts, this expert system will also help its activities as a very experienced assistant.

Forward chaining. forward tracking is a data driven (datadriven) approach. In this approach tracking starts with input information, and then tries to draw conclusions. Forward tracking looks for facts that are in accordance with the IF part of the IF-THEN rules.

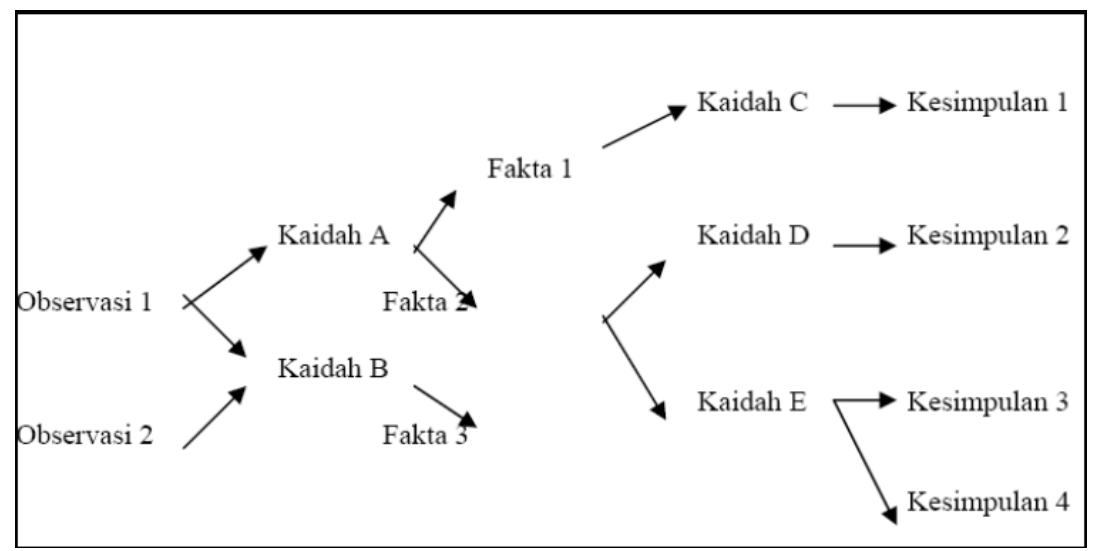

Figure 1. Forward chaining process

Car. Ground vehicles driven by engine power, wheeled four or more (always even), usually using fuel oil (gasoline / diesel) to start the engine. The car stands for car comes from the Greek 'autos' (alone) and Latin 'movére' (move) (Wikipedia, 2014).

Cugnot's discovery of its use was seen lowly in its native France, and the discovery was continued to Britain, where Richard Trevithick ran a steam-wheelbarrow in 1801. The vehicle was considered strange at first, but discoveries in the decades that followed, such as hand brakes, multi-transmission speed, and increased speed and steering, make it a success. Today, America has more cars than any other country. Japan leads the car manufacturing, but the Japanese population cannot afford to run the car because of the scarce parking space and high fuel prices.

Relational. the most important part in a database. Relational is used to create relationships between logically related entities. Two different entities can have a relationship using relational.

Database. Ahmad Sholihin (2009: 1), Database is a collection of tables that relate to one another stored on computer hardware by using software to manipulate it.

\subsection{System General Design.}

System design procedures in general for the development of expert systems to identify damage to the car consists of several stages, including the design:

a. Data

The design of the intended data is the design of data relating to making applications, 
including:

- Input data

Including supporting data as input for making the system.

- Output data

From the input data, how the system will use to obtain new data as the system output.

\section{b. Process}

The design process that is intended is how the system will work, what processes are used, starting from the entry of input data which is then processed by the system to become output data.

\section{c. Interface}

Interface design here contains an explanation of the use of trees and their information as well as the data structure used by the system that has been built.

d. System Design Description. The design of this system consists of several stages which will be described including:

e. Data Design. In designing data, it is explained how the data contained in the system in accordance with its function as input data or system output data.

\section{f. Symptom data}

\section{Overheat}

Symptoms:

a. Oil leak

b. The oil indicator light on the dash lights up

c. Leaks in engine seals

d. The engine works beyond the working temperature limit

\section{g. Preventive steps:}

Check the amount of oil regularly - check the cooling system - watch for temperature indicators when symptoms of knocking occur.

\section{h. Water hammer}

Symptoms:

a. Water fills the combustion chamber.

b. Water pressure destroys the weakest components in the combustion chamber.

c. The entry of water into the combustion chamber.

d. The engine works beyond the working temperature limit

Preventive steps:

Know the height of the air intake in the car before standing water - do not start the engine in flood conditions - open the spark plugs and start the engine to remove the water in the combustion chamber.

\section{i. Timing belt}

Symptoms: 
a. The belt broke suddenly.

b. Piston mashing valve.

c. The piston shook violently.

d. Oil leak.

e. The engine works beyond the working temperature limit.

Preventive steps:

Change the timing belt periodically according to the recommendation - speed up the change of the timing belt if the car often crosses the road.

\subsection{Decision Table Analysis}

Decision tables are used as a reference in making decision trees and the rules used.

Based on the analysis of the problem of damage and symptoms above, the decision table in the expert system identifies the damage to the car can be seen in table1.

Table 1. Decision Table

\begin{tabular}{|c|c|c|c|c|}
\hline \multirow{2}{*}{ SYMPTOMS } & \multicolumn{4}{|c|}{ DAMAGE } \\
\hline & K001 & K002 & K003 & K004 \\
\hline G001 & $\mathrm{X}$ & & $\mathrm{X}$ & \\
\hline G002 & $\mathrm{x}$ & & $\mathrm{x}$ & \\
\hline G003 & & & $\mathrm{x}$ & \\
\hline G004 & $\mathrm{x}$ & $\mathrm{x}$ & & $\mathrm{X}$ \\
\hline G005 & & $\mathrm{x}$ & & \\
\hline G006 & & $\mathrm{x}$ & & \\
\hline G007 & $\mathrm{x}$ & & & \\
\hline G008 & & & $\mathrm{X}$ & \\
\hline G009 & & & & $\mathrm{X}$ \\
\hline G010 & & $\mathrm{x}$ & & \\
\hline G011 & & & & $\mathrm{X}$ \\
\hline G012 & & & & $\mathrm{X}$ \\
\hline G013 & & & $\mathrm{X}$ & $\mathrm{X}$ \\
\hline
\end{tabular}

Damage description:

K001 : Overheat

K002 : Water hammer

K003 : Timing belt

K004 : The engine block brokel

Description of symptoms:

G001 : Oil leak.

G002 : The engine works beyond the working temperature limit.

G003 : The belt broke suddenly.

G004 : The oil indicator light on the dashboard lights up.

G005 : Water pressure destroys the weakest component er

G006 : The entry of water into the combustion chamber.

G007 : Leaks in engine seals.

G008 : The piston shook violently.

G009 : Tickling machine.

G010 : Water fills the combustion chamber.

G011 : Clash of engine blocks many times.

G012 : Often add speed beyond the limits.

G013 : Valve-pounding piston. 


\section{Discussion}

\subsection{Analysis of the Tracking Method}

The tracking method used in building an expert system to identify damage to the car is Forward Chaining. Using the Forward Chaining method, all symptom data and rules will be traced to obtain damage information detected by an expert system for identifying damage to the car.

\subsection{Analysis of Search Methods}

The search method used in building expert systems to identify damage to cars is the best-first-search method. The best-first-search search process checks all nodes (symptoms) until the destination node is found. This method is used to make the search process more effective, finding solutions without having to test more in a state space.

\subsection{Decision Tree Analysis}

Formation of a decision tree in the expert system to identify damage to the car using a binary tree. This decision tree combined with the best-first-search method, can be seen in Figure 1 below:
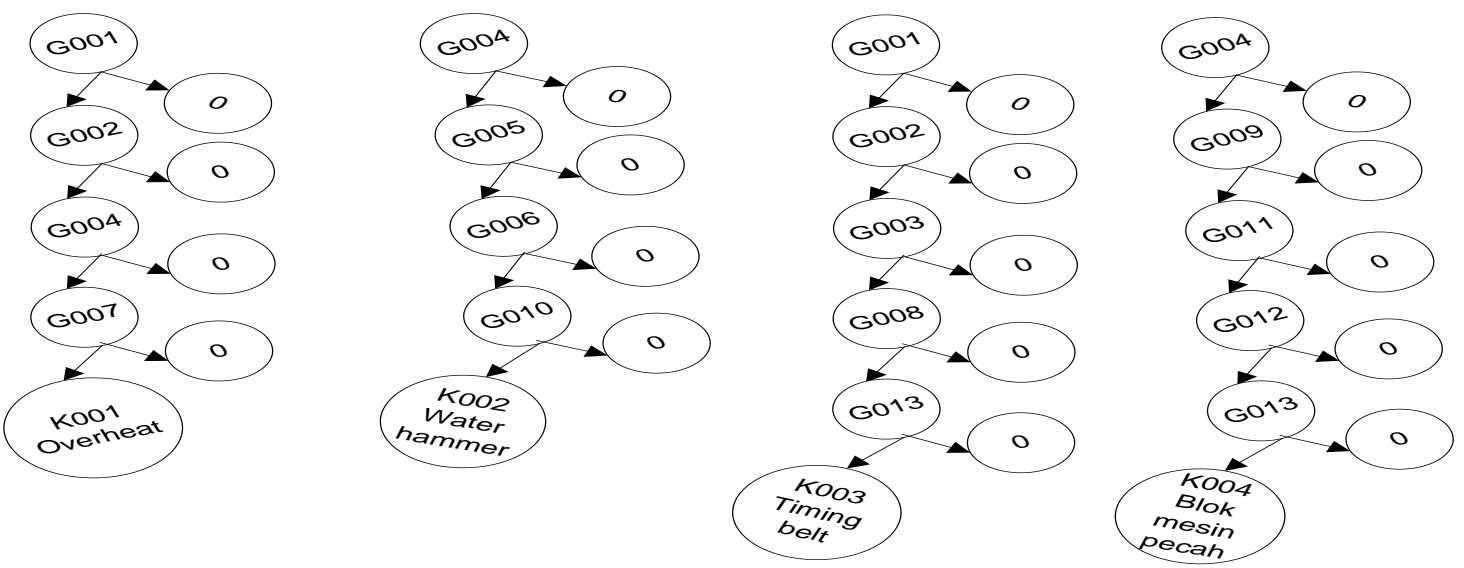

Note :

Figure 1. The best first search decision tree

\subsection{Design of Entity Relationship Diagram (ERD)}

Taking into account the data and information that will be used in the process of building this application, then two database designs are built that are interconnected by using the Entity Relational Diagram (ERD) tools

\subsection{Database Creation}

In making database design, the first step is to create the database itself, namely car damage. Then create tables to hold the data specified. The tables in the expert system to identify damage to the car are:

\section{a. User table}

Function to hold user data which consists of several fields, namely: userID and passID. The table can be seen in table.2. 
Table 2. User table

\begin{tabular}{|c|l|c|c|l|}
\hline No & \multicolumn{1}{|c|}{ Field } & Type & Length & \multicolumn{1}{c|}{ Information } \\
\hline 1 & userID & varchar & 50 & ID the user \\
\hline 2 & passID & varchar & 50 & User password \\
\hline
\end{tabular}

\section{b. Car table}

This table contains car data which has fields: kd_car and nm_car. As for this table, the one that functions as the main keyword is kd_car. The table is seen in table 3 below.

Table 3. Car table

\begin{tabular}{|c|l|c|c|c|}
\hline No & \multicolumn{1}{|c|}{ Field } & Type & Length & Information \\
\hline 1 & kd_car & Char & 4 & Car code (Primari key) \\
\hline 2 & nm_car & varchar & 25 & Car name \\
\hline
\end{tabular}

\section{c. Table of the year}

This table contains disease data that has fields: kd_year and nm_year. As for this table what functions as the main keyword is kd_year. The table is seen in table 4 below.

Table 4. Year table

\begin{tabular}{|c|l|c|c|l|}
\hline No & \multicolumn{1}{|c|}{ Field } & Type & Length & \multicolumn{1}{|c|}{ Information } \\
\hline 1 & kd_year & char & 4 & Year code (Primari key) \\
\hline 2 & nm_year & int & 4 & Year name \\
\hline
\end{tabular}

\section{d. Symptoms table}

This table contains symptoms data inputted by experts. The fields are: kd_symptoms and nm_symptoms. In this table what functions as the main keyword is kd_ symptoms. The table can be seen in table 5 .

Table 5. Symptoms table

\begin{tabular}{|c|l|c|c|l|}
\hline No & \multicolumn{1}{|c|}{ Field } & Type & Length & \multicolumn{1}{c|}{ Information } \\
\hline 1 & kd_symptoms & char & 4 & Symptoms code (Primari key) \\
\hline 2 & nm_symptoms & varchar & 100 & Symptoms code \\
\hline
\end{tabular}

\section{e. Damage table}

This damage table contains data on damage that has fields: kd_er Damage, nm_per Damage and solutions. As for this table that functions as the main keyword is kd_kerusak. The table is seen in table 6 below.

Table 6. Damage table

\begin{tabular}{|c|l|c|c|l|}
\hline No & \multicolumn{1}{|c|}{ Field } & Type & Length & \multicolumn{1}{c|}{ Information } \\
\hline 1 & kd_damage & char & 4 & Malfunction code (Primari key) \\
\hline 2 & nm_damage & varchar & 100 & Damage name \\
\hline 3 & The solution & text & & The solution \\
\hline
\end{tabular}




\section{f. Relationship table}

This table is used to connect damage data with symptom data. This table consists of kd_damaged, $k d_{\text {_ }}$ symptoms, kd_car and kd_year. The table structure can be seen in table 7 .

Table 7. Relationship table

\begin{tabular}{|c|l|c|c|l|}
\hline No & \multicolumn{1}{|c|}{ Field } & Type & Length & \multicolumn{1}{c|}{ Information } \\
\hline 1 & kd_damage & char & 4 & Malfunction code \\
\hline 2 & kd_symptoms & char & 4 & Symptom code \\
\hline 3 & kd_car & char & 4 & Car code \\
\hline 4 & kd_year & char & 4 & Year code \\
\hline
\end{tabular}

\section{g. The tmp_Conceptualizer Table}

This table functions to collect consultants data which consists of several fields, namely: id, name, sex, address, occupation, kd_car, kd_year, noip and date. In this table the main keywords are id. The table can be seen in table.8.

Table 8. Table of conceptualizer

\begin{tabular}{|c|l|c|c|l|}
\hline No & \multicolumn{1}{|c|}{ Field } & Type & Length & \multicolumn{1}{c|}{ Information } \\
\hline 1 & id & int & 4 & Id pengkonsul (Primari key) \\
\hline 2 & name & varchar & 25 & Name \\
\hline 3 & sex & enum & ('L',P') & Gender \\
\hline 4 & address & varchar & 100 & Address \\
\hline 5 & occupation & varchar & 30 & Occupation \\
\hline 6 & kd_car & char & 4 & Car code \\
\hline 7 & kd_year & char & 4 & Year code \\
\hline 8 & noip & varchar & 15 & Internet Protocol Number \\
\hline 9 & date & datetime & & Date \\
\hline
\end{tabular}

\section{h. Tmp_analysis table}

This table is used to temporarily store damage analysis data on the car during the consultation process. This table consists of noip, $\mathrm{kd}_{-}$damaged, $\mathrm{kd}$ - symptoms, kd_car, year_code and status. The table structure can be seen in table 9 .

Tabel 9. Tmp_Analysis Table

\begin{tabular}{|c|l|c|c|l|}
\hline No & \multicolumn{1}{|c|}{ Field } & Type & Length & \multicolumn{1}{c|}{ Information } \\
\hline 1 & noip & varchar & 15 & Internet Protocol Number (Primari key) \\
\hline 2 & kd_damaged & char & 4 & Malfunction code \\
\hline 3 & kd_symptoms & char & 4 & Symptom code \\
\hline 4 & kd_car & char & 4 & Car code \\
\hline 5 & kd_year & char & 4 & Year code \\
\hline 6 & status & enum & 'Y','N' & Answer status (Foreign key) \\
\hline
\end{tabular}

\section{i. Symptom table}

This table is used to temporarily store data on the symptoms of damage during the process of diagnosis by the counselor. This table consists of kd_ symptoms and noip. The 
table structure can be seen in table 10 .

Table 10. Table of Symptoms

\begin{tabular}{|c|l|c|c|l|}
\hline No & \multicolumn{1}{|c|}{ Field } & Type & Length & \multicolumn{1}{c|}{ Information } \\
\hline 1 & $\begin{array}{l}\text { kd_ } \\
\text { symptoms }\end{array}$ & char & 4 & Symptom code (Primari key) \\
\hline 2 & noip & varchar & 15 & Internet Protocol Number \\
\hline
\end{tabular}

\section{j. Damage tmp table}

This table is used to temporarily store damage data during the diagnostic process by the drafter. This table consists of kd_ damaged and noip. The table structure can be seen in table 11.

Table 11. Damage tmp table

\begin{tabular}{|c|l|c|c|l|}
\hline No & \multicolumn{1}{|c|}{ Field } & Type & Length & \multicolumn{1}{c|}{ Information } \\
\hline 1 & $\begin{array}{l}\text { kd_ } \\
\text { symptoms }\end{array}$ & char & 4 & Malfunction code (Primari key) \\
\hline 2 & noip & varchar & 15 & Internet Protocol Number \\
\hline
\end{tabular}

\section{k. The tmp_car table}

This table is used to temporarily store car data during the diagnostic process by the drafter. This table consists of kd_car and noip. The table structure can be seen in table 12 .

Table 12. Car tmp table

\begin{tabular}{|c|l|c|c|l|}
\hline No & \multicolumn{1}{|c|}{ Field } & Type & Length & \multicolumn{1}{c|}{ Information } \\
\hline 1 & kd_car & char & 4 & Car code (Primari key) \\
\hline 2 & noip & varchar & 15 & Internet Protocol Number \\
\hline
\end{tabular}

\section{Table year}

This table is used to temporarily store year data at the time of the diagnosis process by the drafter. This table consists of kd_year and noip. The table structure can be seen in table13.

Table 13. Table year

\begin{tabular}{|c|l|c|c|l|}
\hline No & \multicolumn{1}{|c|}{ Field } & Type & Length & \multicolumn{1}{c|}{ Information } \\
\hline 1 & kd_year & char & 4 & Year code (Primari key) \\
\hline 2 & noip & varchar & 15 & Internet Protocol Number \\
\hline
\end{tabular}

\section{m. Results analysis table}

This table is used to store identification data. This table consists of id, name, sex, address, damage, kd_mobil, kd_tahun, noip and date. In this table, id is the primary key while kd_c Damage is a foreign key. The table can be seen in table 14. 
Table 14. Results analysis table

\begin{tabular}{|c|l|c|c|l|}
\hline No & \multicolumn{1}{|c|}{ Field } & Type & Length & \multicolumn{1}{c|}{ Keterangan } \\
\hline 1 & id & int & 4 & Id patient (Primari key) \\
\hline 2 & name & varchar & 60 & The author's name \\
\hline 3 & sex & enum & $\left(' L^{\prime}, \mathrm{P}^{\prime}\right)$ & Gender \\
\hline 4 & address & varchar & 100 & Address \\
\hline 5 & kd_damage & char & 4 & Malfunction code \\
\hline 6 & kd_car & char & 4 & Car code \\
\hline \hline 7 & kd_year & char & 4 & Year code \\
\hline 8 & noip & varchar & 15 & Internet Protocol Number \\
\hline 9 & date & datetime & & Date of diagnosis \\
\hline
\end{tabular}

\subsection{Context Diagram Design}

Context diagram is a general description of a system that is designed globally, which is a diagram that presents or illustrates the relationship between the system and the environment outside the system that affects system operation. The system is shown in an environment that describes the whole process in the system and its relationship with the entity. There are two entities that are directly connected to the system, the conceptor and the expert / admin. The context diagram of this expert system can be seen in Figure 3.4.

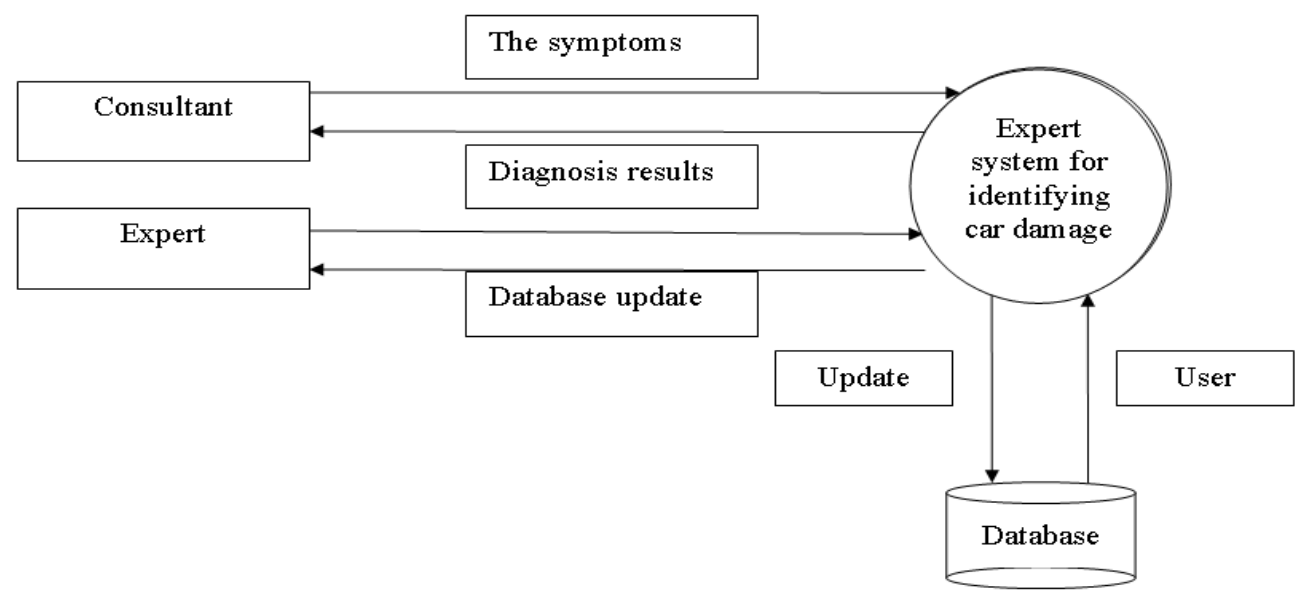

Figure 2. Context Diagram

\subsection{Data Flow Diagrams / Data Flow Diagrams}

Data flow diagrams / data flow diagrams are graphical techniques that describe the flow of information and transformations that are applied when data moves from input to output.

Data flow diagrams are used to present a system or software at each level of abstraction. Data flow diagrams can be partitioned into levels that represent an increased flow of information. Data flow diagrams provide a mechanism for functional modeling and information flow modeling. Data flow diagrams for expert systems to identify damage to web-based cars are shown in figures 3.5 through figure 3.8.

\section{a. Data flow diagram level 0}

Level 0 data flow diagrams have four main processes with two entities (Expert / admin) and conceptualizer 


\section{b. Level 1 data flow diagram}

Level 1 data flow diagram illustrates the knowledge base processing including symptom data processing, damage data processing, symptom relation data processing and conceptual diagnosis.

\section{c. Process 2 level 2 data flow diagram (expert / admin)}

Process 2 level 2 data flow diagram (expert / admin) is a decrease from level 1 data flow diagram that illustrates the processing of expert knowledge base including symptom data processing, damage data processing and data processing of damage-symptom relations.

\section{d. Process 2 level 3 data flow diagram (draft)}

Process 3 level 2 data flow diagram (conceptual) is a decrease from level 1 data flow diagram which illustrates the diagnostic process carried out by the conceptor.

\subsection{Diagnosis Process}

Displays questions in the form of symptoms that are in the database. In using the concept, it is enough to check True (Yes) or False (No) to answer the questions that are displayed. Displays questions in the form of symptoms in the database. In using the concept, it is enough to check True (Yes) or False (No) to answer the questions that are displayed. Processing data relation between damage and symptoms. The relationship between damage and symptoms needs to be done so that there is a synchronization between damage and symptoms. Determination of the rules used for the diagnosis process is also done here. The display page of the input relation damage and symptoms.

\subsection{Diagnosis Results}

The results of this diagnosis are the final output (output) of the diagnostic process that has been carried out by the counselor. This report displays the results of the diagnosis of damage to the car.

\section{Conclusion}

After testing and analyzing the program, it can be concluded as a user system that has been made able to do the data reasoning process with the forward chaining method. Admin can do the process of adding data symptoms, damage and manage relationships. Admin can print reports that exist in the expert system identification of damage to the car. Expert system to identify damage to the car can make it easier for users to find solutions to the problem of car damage.

Suggestions from some conclusions that have been taken, then obtained suggestions that will help for the further development of this software. It is necessary to add data for damage and symptoms so that the information held will be more extensive and more extensive. In the admin system, if there is the addition of more complex data, the admin must design a more flexible database making it easier to perform system management. Training must be done so that the admin on this system can work faster. It is expected that this expert system must have system maintenance that will be carried out by the programmer himself. So that the system can work well. 


\section{References}

Arbie, A.F. (2013). Sistem Pakar Dalam Mengidentifikasi Jenis Kerusakan Mesin Pada Mobil Suzuki Carry Berbasis Web. Universitas Sam Ratulangi, Manado.

Havery, L. James, (2002). Everithing About Sistem, Penerbit Harvest Day Books, London. Jogiyanto H.M. (2001). Sistem Informasi Akutansi. Andi, Yogyakarta.

Kadir, Abdul. (2003). Dasar Pemrograman WEB Dinamis menggunakan PHP. Penerbit Andi Offset, Yogyakarta.

Kusumadewi, S. (2003). Artificial Intelegence (Teknik dan Aplikasinya). Yogyakarta, Graha Ilmu.

Mc Manama, John, (2009). Systems Analysis for Effective, School Administration, Parker Publishing Coy.

Perangin angin, Kasiman, 2010. Aplikasi Web dengan PHP dan MySQL. Andi, Yogyakarta.

Rizal (2011). Diagnosa Kerusakan Mesin Tipe OM366A Pada Mobil Mercedes-Benz Menggunakan Sistem Pakar. Universitas Malikussaleh, Lhokseumawe.

Solihin, Ahmad. (2010). MySQL 5 Dari Pemula Hingga Mahir. Universitas Budi Luhur, Jakarta.

Solihin, Ahmad. (2009). Pemograman Web Dengan PHP dan MySQL. Universitas Budi Luhur, Jakarta.

Yudatama, Uky (2008). Sistem Pakar Untuk Diagnosis Kerusakan Mesin Mobil Panther Berbasis Mobile. Universitas Muhammadiyah, Magelang. 